\title{
Actitudes hacia la enseñanza de las lenguas indígenas
}

\section{Carmen Rojas Chaves}

Departamento de Educación Indígena

Ministerio de Educación Pública, Costa Rica

En Costa Rica existen 8 culturas indígenas, distribuidas en los 24 territorios indígenas. De acuerdo con el censo del año 2000, la población indígena es de 63.800 personas, lo que representa un $1.7 \%$ de la población total del país. Un $42 \%$ de esta población vive en los territorios indígenas; un $31 \%$ en zonas aledañas y un $27 \%$ en el resto del país.

Se reconoce oficialmente la existencia de 6 lenguas indígenas - cabécar, bribri, guaymí, malecu, boruca y térraba-, pero en realidad se hablan 8 , porque hay un importante grupo de misquitos que mantiene su lengua y también porque con el término "guaymî" se designan dos lenguas: el ngäbere y el buglere.

No se cuenta con datos precisos sobre la cantidad de hablantes de lenguas indígenas. Según el censo del año 2000, de los 27.032 indígenas que viven en los territorios indígenas, unos 15.500 hablan una lengua indígena como lengua materna. No obstante, esta cifra debe manejarse con reservas, porque contiene algunos datos que no pueden considerarse veraces, como por ejemplo, la existencia de hablantes del huetar y del chorotega, dos lenguas. extintas desde hace varios siglos, y un número de hablantes del cabécar mucho menor al reportado según otros censos, entre ellos los realizados por el Ministerio de Salud.

Todas las lenguas indígenas muestran un gran debilitamiento en relación con los siglos pasados. No obstante, la vitalidad de la lengua 
varía no solo de un territorio a otro, sino también en las comunidades comprendidas dentro de un mismo territorio indígena.

La realidad sociolingüística de las comunidades indígenas es diversa y compleja. Los niños ingresan al sistema escolar con diferentes niveles de conocimiento y de uso de las lenguas autóctonas y del español. Es posible encontrar niños monolingües en la lengua indígena, monolingües en español, bilingües en dos lenguas indígenas, con manejo de una lengua indígena y algún conocimiento del español, con mane jo del español y algún conocimiento de una lengua indígena, así como niños trilingües. Con frecuencia, en cada uno de los grupos que atiende el maestro encontramos una muestra de esta diversidad.

Desde su creación, en 1995, el Departamento de Educación Indígena del Ministerio de Educación Pública desarrolla un programa de enseñanza de las lenguas indígenas. Como antecedente inmediato de este programa está la iniciativa que la Escuela de Filología de la Universidad de Costa Rica inició a finales de 1990, para la enseñanza de la lengua boruca en la Escuela Doris Stone, del territorio indígena Boruca. Se contrató a una persona de la comunidad para que impartiera lecciones de lengua boruca, como segunda lengua, a los niños de la escuela.

A partir de 1995, el proyecto fue asumido por el Departamento de Educación Indígena y paulatinamente se ha ido expandiendo a otras comunidades.

El objetivo fundamental del Programa de Enseñanza de las Lenguas Indígenas es revitalizar y difundir las lenguas indígenas del país mediante su enseñanza a los niños y jóvenes de los territorios indígenas.

La ejecución de este programa está a cargo de 56 docentes (52 en primaria y 4 en secundaria), todos miembros de las comunidades indígenas, hablantes fluidos de la lengua indígena y amplios conocedores de la cultura tradicional. La cobertura actual es del $70 \%$ de la población estudiantil dentro de los territorios indígenas, porcentaje que aumenta cada año. Además, como plan piloto, se atienden 4 preescolares bilingües (cabécar y español) en Chirripó. 
La inclusión de los cursos de lenguas indígenas en el plan de estudios de las comunidades indígenas obedece a la solicitud de un gran número de estudiantes, padres de familia y dirigentes comunales, determinada mediante diagnósticos socioeducativos realizados en diversos territorios indígenas durante 1994 y 1995. La petición variaba entre incluir la lengua indígena como segunda lengua o como lengua de enseñanza.

Ahora bien, si partimos de que los programas escolares responden a una selección de saberes que contribuyen al desarrollo de competencias deseables en los individuos de una sociedad, la inclusión de la enseñanza de las lenguas indígenas en el sistema educativo formal, ya indica una valoración positiva hacia la lengua indígena por parte de los miembros de esa comunidad, que generalmente es una preocupación por el debilitamiento o extinción de esta lengua.

No obstante, una vez que esta demanda fue atendida, en los primeros años del programa hubo reacciones adversas por parte de muchos padres de familia, fundamentadas, entre otras causas, en el temor de que esto significara que a sus hijos no se les iba a enseñar a hablar el español, o que las lecciones de lengua indígena disminuyeran el número de lecciones de las materias básicas. También en los cambios de horario que debieron hacerse y en algunos conflictos que surgieron entre los docentes.

Los niños, desde el inicio del programa, han tenido una actitud positiva hacia el aprendizaje de las lenguas indígenas, en la mayoría de los casos.

Esto se hace evidente en algunas investigaciones, como la realizada por la señora Elsa Potter, estudiante de doctorado en Educación, en la Universidad de Kansas, quien, a pesar de hallar deficiencias en cuanto a la metodología utilizada por los docentes de lengua bribri de tres escuelas de Talamanca, destaca el interés de los niños en el aprendizaje de esta lengua y en la tesis para optar por el grado de licenciatura en Ciencias de la Educación presentada por Elizabeth Alguera Sánchez y Francisco Salomón Ortiz Ortiz. Este último estudio se 
realizó en el territorio indígena de Coto Brus, en 1998, un año después de que el programa se inició en algunas comunidades de ese territorio. En las conclusiones, indican que de acuerdo con lo informado por los alumnos, les gusta "aprender a escribir en idioma guaymî" y en general, "les agradan e interesan las lecciones impartidas por el maestro itinerante de idioma guaymî".

Otros indicadores de la aceptación del Programa de Enseñanza de las Lenguas Indígenas son los siguientes:

- Una continua petición de nuevos códigos para ampliar el programa.

- La demanda de los estudiantes del Colegio Sulàyöm, de Talamanca, de que las lenguas bribri y cabécar puedan considerarse como asignatura de evaluación en las pruebas de bachillerato.

- $\quad$ La solicitud de vecinos de diferentes comunidades talamanqueñas y de Chirripó de que en algunas comunidades se impartan lecciones de dos lenguas indígenas (bribri y cabécar o ngäbere y buglere).

- La demanda de los padres de familia para elaborar programas de alfabetización de adultos, en las lenguas indígenas o de que se les incorpore en cursos de lenguas indígenas.

- Hay una demanda de que los docentes generales sean también bilingües y de que los cursos de lenguas indígenas se amplíen a la educación preescolar y a la telesecundaria.

En Talamanca, durante el 2001 se realizó una investigación interna que hace evidente la apertura hacia la enseñanza de las lenguas indígenas, una correlación entre la existencia de este servicio y una disminución en los índices de deserción escolar, reprobación y repitencia.

Ese mismo año, se pasó una encuesta a 83 padres de familia cabécares del territorio indígena Tayní (Valle de La Estrella) y el $100 \%$ respondió que estaba de acuerdo con la enseñanza de la lengua indígena. Fundamentaron su aprobación en razones como la importancia de mantener la lengua y la cultura y de aprender a leer y escribir en 
cabécar, el interés en que sus hijos conocieran la lengua y cultura autóctonas y fortalecieran su identidad cultural y la facilidad que tiene el niño para aprender cuando se le enseña en la lengua que domina.

Los padres muestran una mayor conciencia de que la tarea de enseñar el cabécar como lengua materna les corresponde a ellos y de que deben asumir una responsabilidad en relación con la permanencia de la lengua indígena. Hay también una recuperación de los espacios de uso de la lengua indígena en las comunidades, en diferentes actividades locales. Como puede verse, se ha logrado promover entre los padres de familia y los estudiantes una actitud positiva en favor de la enseñanza de las lenguas indígenas.

Los padres de familia que están en desacuerdo aducen razones como que ya sus hijos hablan la lengua indígena, que los maestros son vecinos de la comunidad, sin un título universitario que los respalde o que les da miedo que los niños se confundan. También influye el hecho de que los maestros de lengua indígena son itinerantes, atienden entre 2 y 4 escuelas y pertenecen a alguna de las comunidades del territorio indígena, por lo que la variante dialectal que hablan no siempre es la misma que la de sus alumnos. Esto motiva a algunos padres a decir que el docente no habla "bien" la lengua indígena.

Si bien por ahora no es posible evaluar el impacto del programa, sí es posible notar un cambio en la apreciación y en la importancia que se le da a las lenguas indígenas y ese cambio cultural posiblemente será el que a largo plazo contribuya a su fortalecimiento y difusión. 